\title{
Universal Basic Income: The Promise vs the Practicalities
}

The idea of a universal basic income (UBI) is nothing new: the concept of a guaranteed endowment paid by the government to each of its citizens dates back centuries. The UBI has gained momentum in recent years as the relative economic stability of the second half of the 20th century gave way to a more turbulent start to the new millennium. The limits of the free market and globalisation in providing a decent standard of living for every citizen were laid bare for all to see, and inequality widened in even the richest global economies. Added to this was the increasing complexity of social security systems in modern welfare states. Policymakers and civil servants had the unenviable task of deciding who was deserving of assistance, as well as policing those in the system to make sure advantage was not being taken. Proponents argue that a UBI, by simply trusting everyone with a basic income each month, could solve both of these issues. Moreover, it could also be the solution to the purportedly imminent destruction of traditional jobs due to the rise of robotics and artificial intelligence. While the idea of a UBI is intriguing, real-world implementation is anything but basic. No serious answers have been found to the question of how to finance such a system, and until a workable solution is found, a UBI is simply not feasible. Other issues that economists continue to research include the negative effects of a UBI on a person's willingness to work and the proper size of a UBI in order to fulfil its intended purpose. The following five articles in this Forum deal with these issues in order to analyse the strengths and weaknesses of what will surely be a major topic of debate over the next decade and beyond.

The Basics of Basic Income

John Kay, St John's College, Oxford, UK.

On the Economics of a Universal Basic Income

Thomas Straubhaar, University of Hamburg, Germany.

Universal Basic Income Financing and Income Distribution - The Questions Left Unanswered by Proponents

Heiner Flassbeck, Makroskop Mediengesellschaft mbH, Wiesbaden, Germany.

Universal Basic Income - Empty Dreams of Paradise

Hilmar Schneider, Institute of Labor Economics (IZA), Bonn, Germany.

\section{Basic Income in the Finnish Context}

Olli Kangas, Kela/Social Insurance Institution, Helsinki, Finland.

Miska Simanainen, Kela/Social Insurance Institution, Helsinki, Finland.

Pertti Honkanen, Kela/Social Insurance Institution, Helsinki, Finland. 